\title{
Endovascular strategies for carotid cavernous and intracerebral dural arteriovenous fistulas
}

\author{
Perry P. Ng, M.D., Randall T. Higashida, M.D., Sean Cullen, M.D., \\ Reza MaleK, M.D., Van V. Halbach, M.D., ANd Christopher F. Dowd, M.D. \\ Division of Interventional Neuroradiology, University of California at San Francisco Medical Center, \\ San Francisco, California
}

\begin{abstract}
Interventional neuroradiology is a less invasive modality than open neurosurgery for the treatment of a wide range of neurovascular disorders. Refinements in technique and improvements in the design of microcatheters, guide wires, and embolic materials have yielded superior clinical outcomes and provided an impetus to treat more of these lesions endovascularly rather than surgically. Endovascular therapy is the standard of care for direct and indirect carotid artery cavernous sinus fistulas and may also be curative for dural arteriovenous fistulas (AVFs) in other locations.

The authors provide review of the clinical features, pathophysiology, and management of intracranial AVFs focusing on contemporary endovascular treatment options.
\end{abstract}

\section{KEY WORDS • embolization • carotid artery • cavernous sinus • intracranial • arteriovenous fistula $\bullet$ transvenous approach}

Carotid artery cavernous fistulas can be classified in two ways: as "direct," consisting of a tear in the wall of the cavernous ICA causing an arteriovenous communication with the cavernous sinus; or as "indirect," which is synonymous with a DAVF in communication with the cavernous sinus.

Transarterial-transfistula balloon embolization for direct-type fistulas and transvenous coil embolization of indirect fistulas are often curative. Intracranial DAVFs in other locations may also be embolized transarterially or transvenously. Those that are incurable by endovascular embolization alone are usually amenable to preoperative embolization for minimization of intraoperative bleeding.

A thorough review of these lesions and the current endovascular strategies for their treatment is presented along with a range of clinical results.

\section{DIRECT CACFS}

Direct CACFs may be spontaneous or acquired lesions.

\footnotetext{
Abbreviations used in this paper: $\mathrm{CA}=$ carotid artery; $\mathrm{CACF}=$ $\mathrm{CA}$ cavernous fistula; $\mathrm{CCA}=$ common $\mathrm{CA}$; DAVF = dural arteriovenous fistula; $\mathrm{ECA}=$ external $\mathrm{CA}$; $\mathrm{ICA}=$ internal $\mathrm{CA}$; $\mathrm{VA}=$ vertebral artery.
}

Closed head injury in which the base of the skull has fractured and the ICA sheared from its dural attachment to the foramen lacerum and anterior clinoid process are the most common cause of this lesion. Alternative origins include rupture of an intracavernous ICA aneurysm, iatrogenic injury during transsphenoidal pituitary resection, fibromuscular dysplasia, or collagen vascular diseases such as Marfan syndrome and Ehlers-Danlos syndrome. ${ }^{6,8,27}$

\section{Clinical Presentation}

Direct irritation or associated trauma to the cranial nerves traversing the cavernous sinus can result in third, fourth, fifth, and sixth nerve palsies. Retrograde flow of arterialized blood through the superior and inferior ophthalmic veins into the orbit may cause proptosis, chemosis, pain, and reduced visual acuity. Retinal perfusion pressure can be compromised to the extent of inducing permanent blindness. ${ }^{9}$ These ocular symptoms may be exacerbated by hypoplasia or thrombosis/occlusion of the inferior petrosal sinuses that can occur as a result of prolonged arteriovenous artery-vein communication.

Sumping of ICA blood flow into the cavernous sinus may compromise antegrade intracranial flow and precipitate hemispherical hypoperfusion if the circle of Willis collateral structures are inadequate. 


\section{Treatment Options}

Intraocular pressures exceeding $40 \mathrm{~mm} \mathrm{Hg}$ or rapidly progressive visual deterioration are indications for emergency therapy to avoid permanent loss of vision. Topical acetazolomide and $\beta$-agonists can reduce intraocular pressure, and lateral canthotomy may be a temporary measure for decompression of orbital contents prior to definitive closure of the fistula.

Diagnostic angiography can demonstrate the extent of intracerebral collateral pathways, the severity of arteriovenous communication, and residual antegrade flow in the ICA beyond the fistula. Various maneuvers can be useful in identifying the exact location of the hole in the ICA. The Mehringer maneuver (Fig. 1 left) consists of inducing CCA compression during contrast injection in- to the ICA. ${ }^{28}$ Compression of the CA during VA injection ( $\mathrm{Hu}-$ ber maneuver) may delineate the fistula site through retrograde opacification via the posterior communicating artery (Fig. 1 right). ${ }^{20}$

The preferred endovascular procedure is transarteraltransfistula balloon embolization to preserve the ICA while the fistula is occluded using detachable silicone balloons passed from it, through the fistula, and into the cavernous sinus. A detachable silicone balloon is tested for leakage and mounted on a suitable microcatheter. A 0.010 -in guide wire can be used to facilitate passage of the catheter-mounted detachable silicone balloon in the presence of CA tortuosity. The balloon is gently inflated as it approaches the fistula site to facilitate its passage through the arterial tear into the cavernous sinus. Once there, it is inflated incrementally during small test injections of contrast through the guiding catheter to determine any change in the degree of shunting and/or compromise of antegrade flow in the ICA. After the correct volume for occluding the fistula while preserving ICA patency has been determined, the balloon is detached by gently pulling back on the catheter (Fig. 2). Filling the balloon with hydroxyethylmethacrylate, which polymerizes within an hour at body temperature, makes the balloon less likely to deflate or migrate than iodinated contrast alone.

If transarterial-transfistula balloon occlusion is not feasible, transvenous coil embolization may be performed us-

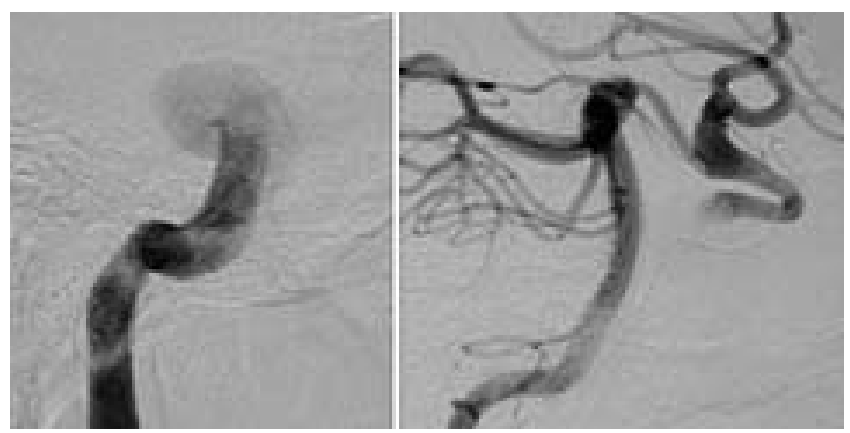

Fig. 1. Techniques for enhanced localization of fistula site. Left: The Mehringer maneuver. Compression of the ipsilateral CCA during slow ICA injection of contrast defines the proximal extent of the fistula site. Right: The Huber maneuver. Compression of the ipsilateral CA during VA injection demonstrates the distal extent of the fistula site. ing a microcatheter positioned in the cavernous sinus via the inferior petrosal sinus. Even when the inferior petrosal sinus cannot be visualized angiographically, a channel can usually be found by probing with a steerable guide wire in up to $75 \%$ of cases. ${ }^{13-15,48}$ Direct percutaneous access to the superior ophthalmic vein in the orbit or, less commonly, the angular facial vein has been reported..$^{25,39}$ Pushable fiber coils are then positioned within the cavernous sinus while avoiding coil prolapse into the ICA through the fistula.

Sacrifice of the ICA may be considered if adequate intracranial collateral pathways exist. Balloon test occlusion can be useful in this regard. Care must be taken to avoid occluding the ICA proximally without complete fistula closure because retrograde shunting could further compromise cerebral perfusion. Using three detachable silicone balloons-one above, one at, and the last one proximal to the site of the fistula-minimizes the risk of this occurrence.

Anecdotal reports of placing a covered stent across the fistula and stent-assisted coil embolization have been described. $^{22,23,36,47}$

\section{INTRACRANIAL DAVFS}

Dural arteriovenous fistulas account for 10 to $15 \%$ of all intracranial arteriovenous shunts. ${ }^{32}$ They are acquired lesions, thought to originate from an insult to a dural venous sinus that stimulates an inflammatory response with subsequent neovascularization, angiogenesis, and development of pathological shunts at the arteriolar level. ${ }^{31}$ The initial insult may be thrombophlebitis, trauma, intracranial surgery, or dural venous thrombosis. Alternatively, the fistula could be the initial event with turbulent arterialized blood flow in the dural venous sinus inciting a process of thrombosis, stenosis, and occlusion. ${ }^{31,40}$

The most common presentation is in perimenopausal women and is least common in men (27\%), suggesting an underlying hormonal influence..$^{32,33,38,42}$ The transverse and sigmoid sinuses are most commonly involved and followed by the cavernous sinus, the latter also referred to as indirect CACFs.

Spontaneous resolution of angiographically proven DAVFs has been reported to occur in 5 to $10 \%$ of cases.

\section{Classification of DAVFs}

Of the various classification systems for DAVFs, perhaps the most widely accepted is that proposed by Merland, et al., ${ }^{29}$ which indicated that the risk of intracranial hemorrhage is related to the venous drainage pattern. Low-risk fistulas exhibit antegrade venous drainage into a venous sinus whereas high-risk fistulas exhibit reflux into cortical vein(s) from the dural venous sinus, or direct drainage into a cortical vein when the adjacent sinus is occluded (Fig. 3 upper and center). The cortical veins develop tortuosity, stenoses, and venous aneurysms that are potential sites of hemorrhage.

Ongoing pathophysiological changes may occur with persistent arteriovenous fistulas and result in venous stenoses and sinus occlusions that develop in cases of lowrisk fistulas, which are then transformed into higher-risk lesions. Any change in the patient's symptoms such as 


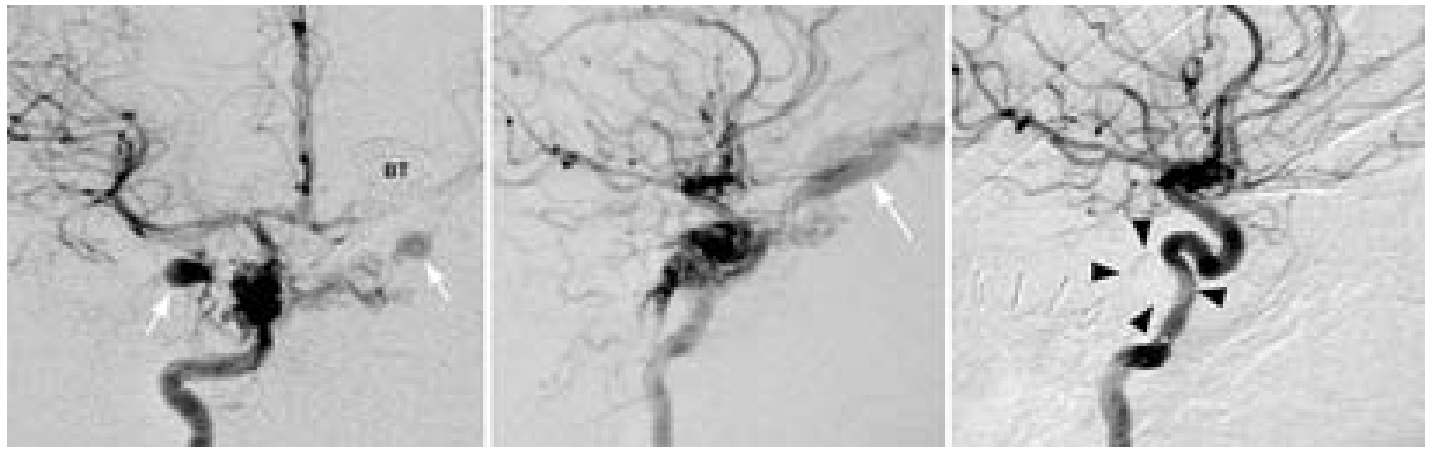

Fig. 2. Angiogram obtained in a 20-year-old man who sustained a gunshot wound to the head. Left and Center: Anteroposterior (left) and lateral right (center) ICA angiograms revealing a direct CACF. Note the dilated superior ophthalmic veins bilaterally (arrows) and outline of the bullet (BT) lodged in the left temporal lobe. Right: Following transarterial-transfistula detachable balloon embolization (arrowheads), there is no residual arteriovenous fistula.

worsening headaches or change in the quality of pulsatile tinnitus may indicate alteration in the venous drainage pattern and risk of hemorrhage. ${ }^{44}$

Both computerized tomography and magnetic resonance imaging may be useful in diagnosis, but conventional catheter arteriography is necessary for definitive diagnosis, risk assessment, and treatment planning. $5,17,43,45,46$

\section{Presentation of DAVFs}

In patients with low-risk fistulas, the lesions may be discovered incidentally during angiography or present with pulsatile tinnitus or headache. High-risk fistulas may present with hemorrhage into the subarachnoid space or brain parenchyma resulting in focal neurological deficits or death. Cortical venous drainage with associated venous hypertension is a well-known cause of neurological deficit and severe headache. ${ }^{21}$ High-risk DAVFs therefore warrant aggressive therapy, either endovascular or surgical, whereas low-risk fistulas can undergo palliative treatment if symptoms such as pulsatile tinnitus are troublesome. ${ }^{4}$

Carotid artery cavernous fistulas may present with ophthalmoplegia, proptosis, chemosis, pain, and reduced visual acuity. Pulse-synchronous bruit is an inconstant finding, occurring in 40 to $50 \%$ of patients. ${ }^{10}$

\section{Treatment Options}

A complete diagnostic cerebral angiography examination is performed to identify the arterial feeding structures in addition to the site of arteriovenous communication within the diseased venous sinus. Typically the ECA is supplied by the ascending pharyngeal, middle and accessory meningeal, occipital, and distal internal maxillary arteries.

The plethora of tortuous feeding arteries often limits the success of transarterial embolization as a definitive treatment. Cure may be achieved if the number of feeding arteries is limited and permanent embolic agents such as n-BCA glue or ethanol can be used safely. Transarterial preoperative embolization involving particulate emboli and coils is of low risk and can significantly reduce intraoperative bleeding.

Arterial feeding structures from branches of the ICA or VAs are usually not amenable to embolization unless microcatheter-based stable superselective catheterization can be performed because reflux of embolic material cannot be afforded. Ethanol may be more suitable in such cases because reflux into the parent artery would be rapidly diluted by antegrade blood flow. Successful embolization of cavernous CA branches has been reported; ${ }^{11}$

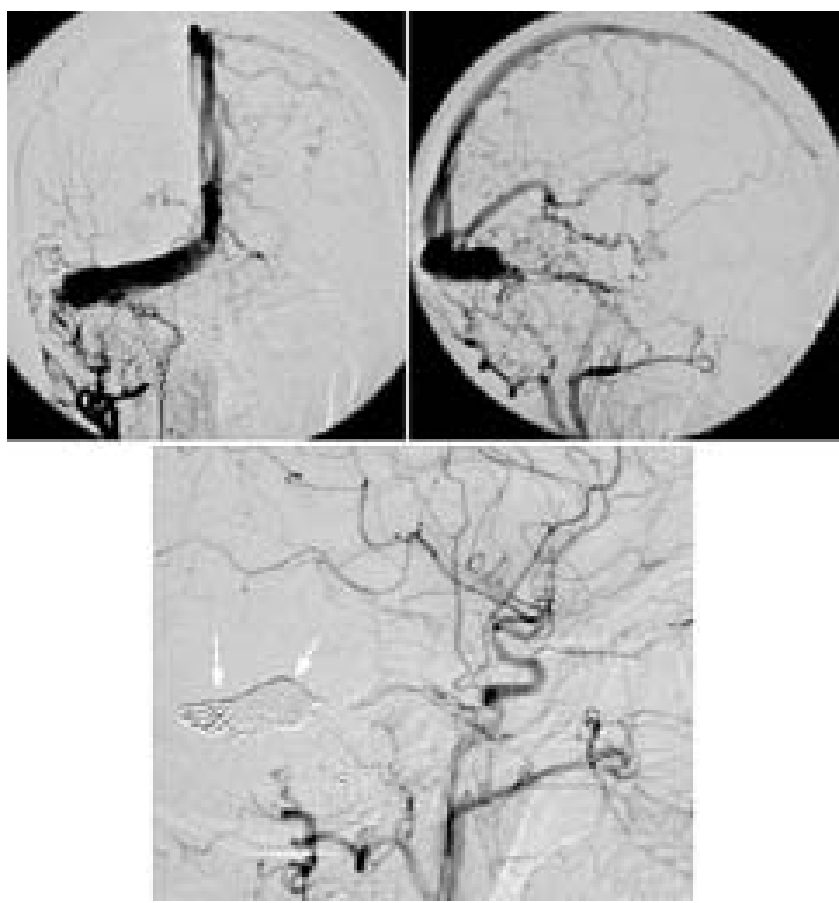

Fig. 3. Angiograms obtained in a 37-year-old woman who experienced headaches and confusion. Upper and Center: Anteroposterior (upper left) and lateral (upper right) ECA angiograms revealing a DAVF at the junction of the right transverse and sigmoid sinuses supplied by numerous feeding arteries. Note the grossly abnormal venous drainage with occlusion of the right sigmoid sinus downstream from the fistula as well as retrograde opacification of the superior sagittal sinus, straight sinus, and reflux into dilated, tortuous cortical veins. Lower: Lateral CCA angiogram obtained after transvenous placement of 30 pushable fibered coils into the fistula and adjacent venous sinus, demonstrating no residual arteriovenous shunting. Note the outline of the coil mass. 
P. P. Ng, et al.

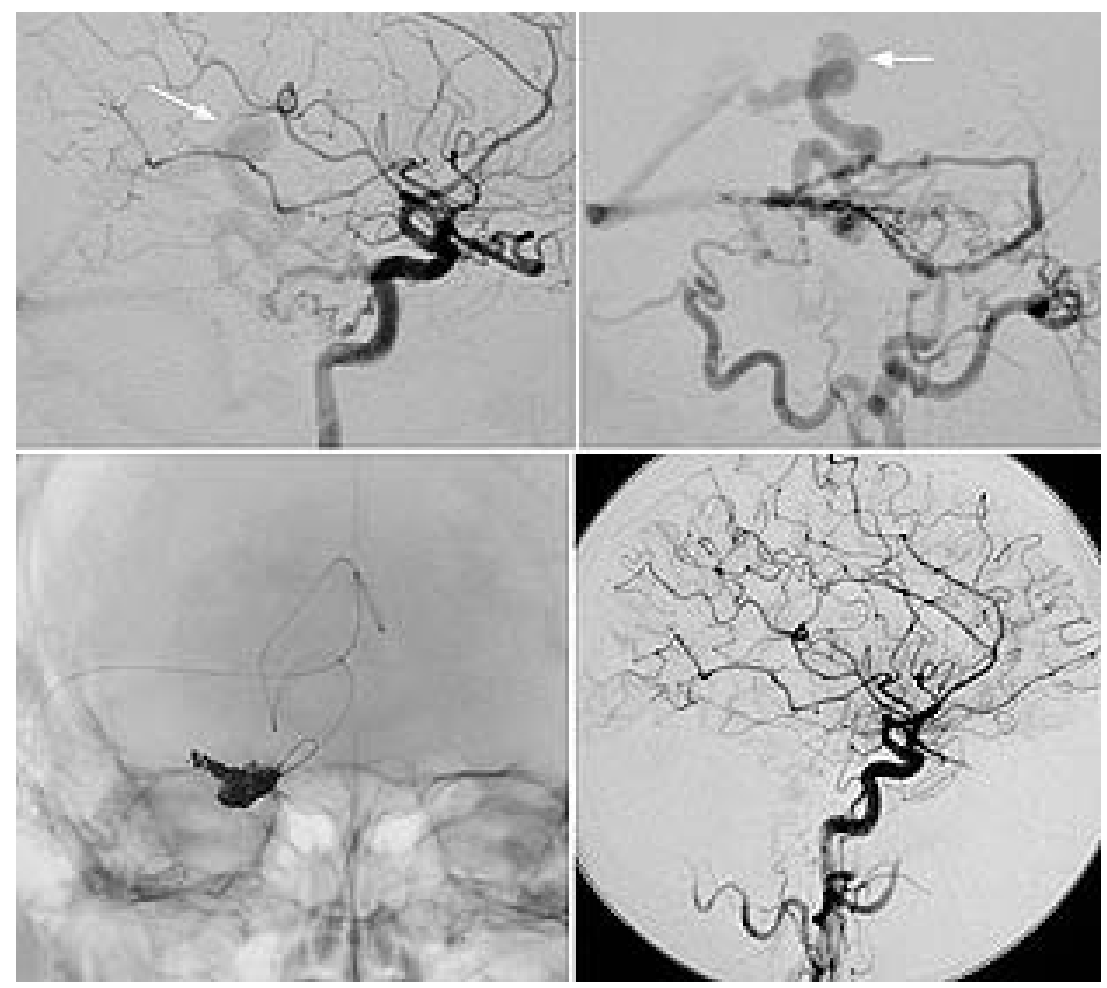

Fig. 4. Angiograms obtained in a 41-year-old man who presented with left-sided hemiparesis due to a right thalamic hemorrhage. Upper Left and Right: Lateral ICA (upper left) and ECA (upper right) angiograms revealing a DAVF of the superior petrosal sinus supplied predominantly by branches of the middle meningeal, occipital, and ophthalmic artery (deep recurrent meningeal branch). The superior petrosal sinus is occluded with consequent cortical venous drainage via the anastomotic lateral mesencephalic vein, which harbors a varix (arrow). Lower Left: Unsubtracted anteroposterior angiogram demonstrating a microcatheter with its tip at the fistula site after having been navigated through the cortical vein and varix via the right sigmoid sinus. Lower Right: After embolization with 15 electrolytically detachable coils, a lateral CCA angiogram demonstrated no residual fistulas.

however, ethanol-based embolization of the meningohypophysial trunk has resulted in posterior pituitary dysfunction and diabetes insipidus. ${ }^{34}$

Conservative treatment for indirect CACFs consists of self-applied CA compression by using the contralateral hand every 30 minutes for 1-minute intervals during waking hours. This can be successful in as many as 30\% of cases. ${ }^{9,14,16}$ By compressing the CA sheath contents, antegrade flow is diminished and venous pressure elevated, promoting thrombosis of the fistula. Should hemiparesis result from CA compression, the contralateral arm will fall away, thus reestablishing cerebral perfusion.

In transvenous embolization of DAVFs, coils are deposited at the site of arteriovenous shunting. When possible, it can result in cure without having to involve the myriad of feeding arteries (Fig. 3 lower). When transvenous access is prevented by occlusion of the recipient venous sinus, the site of shunting can be occasionally accessed transarterially or via a cortical draining vein (Fig. 4). Transcranial embolization after limited craniotomy and direct venous sinus catheterization has been described. ${ }^{18}$ Embolization of indirect CACFs by direct puncture through the superior orbital fissure ${ }^{40}$ and transvenous access to the cavernous sinus via the facial and superficial temporal veins has been reported. ${ }^{3}$
Although detachable coils have the advantage of being able to be repositioned or removed if placement is unsatisfactory, they are significantly more expensive and less thrombogenic than pushable fibered coils. A combination of the two types may be placed as a compromise.

\section{RESULTS OF ENDOVASCULAR TREATMENT}

Chemosis and proptosis typically improve rapidly after successful obliteration of CACFs. Visual acuity and ophthalmoplegia may take longer to resolve and can be exacerbated in the short term by thrombosis and associated swelling within the cavernous sinus. ${ }^{37}$ In a retrospective review of 135 patients with indirect endovascularly treated CACFs, 121 patients (90\%) were clinically cured after a mean follow-up period of 56 months. ${ }^{30}$ In a study of 133 patients undergoing transvenous embolizations for indirect CACFs, good clinical recovery (modified Rankin Scale score of 1-2) was demonstrated in more than $97 \%$ of the population at long-term follow-up examination. . $^{30,35}$ Although uncommon, reversal of blindness after successful embolization of direct and indirect CACFs has been described. $^{2}$

In nine patients in whom transvenous coil embolization was performed for indirect CACFs, two patients suffered 
temporary deterioration of ocular motor function. ${ }^{1}$ There is some evidence that this effect may be limited by the use of corticosteroid agents or heparin in the postoperative period. ${ }^{24}$

High success rates and durable results in direct CACFs can also be achieved when using transarterial-transfistula balloon embolization, and the ICA can also be preserved. ${ }^{7}$ In a review of 87 patients with direct CACFs, detachable balloon embolization allowed ICA preservation; during the mean follow-up period of 10 years, diplopia improved in all patients and there was no recurrence of bruit, chemosis, proptosis or conjunctival edema. ${ }^{26}$

In a recent study of 135 patients in whom endovascular treatment was conducted for intracranial DAVFs, cure was achieved in 74 patients and significant improvement in $54 .{ }^{19}$ In another series of 11 patients with DAVFs of the transverse and sigmoid sinuses, preoperative transarterial embolization was undertaken in seven patients. Endovascular cure was achieved in one of four patients who underwent transvenous embolization, and arteriovenous communication was significantly reduced in the remaining three patients. ${ }^{15}$ In our experience of treating 18 patients with DAVFs of the superior petrosal sinus, four patients (22\%) were cured by transvenous embolization alone. The remaining 14 patients (78\%) underwent preoperative transarterial embolization followed by successful resection of the fistula.

\section{CONCLUSIONS}

Neurovascular embolization therapies can have a role in the treatment of all intracranial arteriovenous fistulas. It is the preferred treatment for both direct and indirect types of CACFs and may be curative for intracranial DAVFs in other locations, particularly when transvenous access to the fistula site can be achieved. In cases in which endovascular cure is not possible, embolization alone can be palliative, or it can be used preoperatively for minimization of intraoperative hemorrhage. Future advances in endovascular equipment in conjunction with technical refinements will expand on the current applications and further minimize procedure-related complications.

\section{References}

1. Aihara N, Mase M, Yamada K, et al: Deterioration of ocular motor dysfunction after transvenous embolization of dural arteriovenous fistula involving the cavernous sinus. Acta Neurochir 141:707-710, 1999

2. Albuquerque FC, Heinz GW, McDougall CG: Reversal of blindness after transvenous embolization of a carotid-cavernous fistula: case report. Neurosurgery 52:233-237, 2003

3. Cheng KM, Chan CM, Cheung YL: Transvenous embolisation of dural carotid-cavernous fistulas by multiple venous routes: a series of 27 cases. Acta Neurochir 145:17-29, 2003

4. Cognard C, Gobin YP, Pierot L, et al: Cerebral dural arteriovenous fistulas: clinical and angiographic correlation with a revised classification of venous drainage. Radiology 194: 671-680, 1995

5. d'Angelo VA, Monte V, Scialfa G, et al: Intracerebral venous hemorrhage in "high-risk" carotid-cavernous fistula. Surg Neurol 30:387-390, 1988

6. Dany F, Fraysse A, Priollet P, et al: [Dysmorphic syndrome and vascular dysplasia: an atypical form of type IV Ehlers-Danlos syndrome.] J Mal Vasc 11:263-269, 1986 (Fr)
7. Desal H, Leaute F, Auffray-Calvier E, et al: [Direct carotidcavernous fistula. Clinical, radiologic and therapeutic studies. Apropos of 49 cases.] J Neuroradiol 24:141-154, 1997 (Fr)

8. Eggers F, Lukin R, Chambers AA, et al: Iatrogenic carotid-cavernous fistula following Fogarty catheter thromboendarterectomy. Case report. J Neurosurg 51:543-545, 1979

9. Halbach VV, Hieshima GB, Higashida RT, et al: Carotid cavernous fistulae: indications for urgent treatment. AJR 149: 587-593, 1987

10. Halbach VV, Higashida RT, Hieshima GB, et al: Dural fistulas involving the cavernous sinus: results of treatment in $30 \mathrm{pa}-$ tients. Radiology 163:437-442, 1987

11. Halbach VV, Higashida RT, Hieshima GB, et al: Embolization of branches arising from the cavernous portion of the internal carotid artery. AJNR 10:143-150, 1989

12. Halbach VV, Higashida RT, Hieshima GB, et al: Endovascular therapy of dural fistulas, in Viñuela F, Halbach VV, Dion JE (eds): Interventional Neuroradiology. Endovascular Therapy of the Central Nervous System. New York: Raven Press, 1992, pp 29-50

13. Halbach VV, Higashida RT, Hieshima GB, et al: Transvenous embolization of direct carotid cavernous fistulas. AJNR 9: 741-747, 1988

14. Halbach VV, Higashida RT, Hieshima GB, et al: Transvenous embolization of dural fistulas involving the cavernous sinus. AJNR 10:377-383, 1989

15. Halbach VV, Higashida RT, Hieshima GB, et al: Transvenous embolization of dural fistulas involving the transverse and sigmoid sinuses. AJNR 10:385-392, 1989

16. Higashida RT, Hieshima GB, Halbach VV, et al: Closure of carotid cavernous sinus fistulae by external compression of the carotid artery and jugular vein. Acta Radiol Suppl 369: 580-583, 1986

17. Hiramatsu K, Utsumi S, Kyoi K, et al: Intracerebral hemorrhage in carotid-cavernous fistula. Neuroradiology 33:67-69, 1991

18. Houdart E, Saint-Maurice JP, Chapot R, et al: Transcranial approach for venous embolization of dural arteriovenous fistulas. J Neurosurg 97:280-286, 2002

19. Huang Q, Li T, Duan C, et al: [Interventional treatment of dural arteriovenous fistula.] Zhonghua Wai Ke Za Zhi 40:682-684, $2002(\mathrm{Chn})$

20. Huber P: A technical contribution of the exact angiographic localization of carotid cavernous fistulas. Neuroradiology 10: 239-241, 1976

21. Hurst RW, Hackney DB, Goldberg HI, et al: Reversible arteriovenous malformation-induced venous hypertension as a cause of neurological deficits. Neurosurgery 30:422-425, 1992

22. Kadyrov NA, Friedman JA, Nichols DA, et al: Endovascular treatment of an internal carotid artery pseudoaneurysm following transsphenoidal surgery. Case report. J Neurosurg 96: 624-627, 2002

23. Kocer N, Kizilkilic O, Albayram S, et al: Treatment of iatrogenic internal carotid artery laceration and carotid cavernous fistula with endovascular stent-graft placement. AJNR 23: 442-446, 2002

24. Kupersmith MJ, Berenstein A, Choi IS, et al: Management of nontraumatic vascular shunts involving the cavernous sinus. Ophthalmology 95:121-130, 1988

25. Labbe D, Courtheoux P, Rigot-Jolivet M, et al: [Bilateral dural carotid-cavernous fistula. Its treatment by way of the superior ophthalmic vein.] Rev Stomatol Chir Maxillofac 88:120-124, 1987 (Fr)

26. Lewis AI, Tomsick TA, Tew JM Jr, et al: Long-term results in direct carotid-cavernous fistulas after treatment with detachable balloons. J Neurosurg 84:400-404, 1996

27. Lister JR, Sypert GW: Traumatic false aneurysm and carotidcavernous fistula: a complication of sphenoidotomy. Neurosurgery 5:473-475, 1979

28. Mehringer CM, Hieshima GB, Grinnell VS, et al: Improved 
localization of carotid cavernous fistula during angiography. AJNR 3:82-84, 1982

29. Merland JJ, Bories J, Djindjian R: Normal and pathological blood supply of the cranial vault. J Neuroradiol 4:95-127, 1977

30. Meyers PM, Halbach VV, Dowd CF, et al: Dural carotid cavernous fistula: definitive endovascular management and longterm follow-up. Am J Ophthalmol 134:85-92, 2002

31. Morris P: Practical Neuroangiography. Baltimore: Williams \& Wilkins, 1997

32. Newton TH, Cronqvist S: Involvement of dural arteries in intracranial arteriovenous malformations. Radiology 93: 1071-1078, 1969

33. Newton TH, Hoyt WF: Spontaneous arteriovenous fistula between dural branches of the internal maxillary artery and the posterior cavernous sinus. Radiology 91:1147-1150, 1968

34. Phatouros CC, Higashida RT, Malek AM, et al: Embolization of the meningohypophyseal trunk as a cause of diabetes insipidus. AJNR 20:1115-1118, 1999

35. Rankin J: Cerebral vascular accidents in patients over the age of 60. II. Prognosis. Scott Med J 2:200-215, 1957

36. Redekop G, Marotta T, Weill A: Treatment of traumatic aneurysms and arteriovenous fistulas of the skull base by using endovascular stents. J Neurosurg 95:412-419, 2001

37. Sergott RC, Grossman RI, Savino PJ, et al: The syndrome of paradoxical worsening of dural-cavernous sinus arteriovenous malformations. Ophthalmology 94:205-212, 1987

38. Taniguchi RM, Goree JA, Odom GL: Spontaneous carotid-cavernous shunts presenting diagnostic problems. J Neurosurg 35:384-391, 1971

39. Teng MM, Guo WY, Huang CI, et al: Occlusion of arteriovenous malformations of the cavernous sinus via the superior ophthalmic vein. AJNR 9:539-546, 1988

40. Teng MM, Lirng JF, Chang T, et al: Embolization of carotid cavernous fistula by means of direct puncture through the superior orbital fissure. Radiology 194:705-711, 1995

41. Terada T, Higashida RT, Halbach VV, et al: Development of acquired arteriovenous fistulas in rats due to venous hypertension. J Neurosurg 80:884-889, 1994

42. Toya S, Shiobara R, Izumi J, et al: Spontaneous carotid-cavernous fistula during pregnancy or in the postpartum stage. Report of two cases. J Neurosurg 54:252-256, 1981

43. Turner DM, Vangilder JC, Mojtahedi S, et al: Spontaneous intracerebral hematoma in carotid-cavernous fistula. Report of three cases. J Neurosurg 59:680-686, 1983

44. Urtasun F, Biondi A, Casaco A, et al: Cerebral dural arteriovenous fistulas: percutaneous transvenous embolization. Radiology 199:209-217, 1996

45. Vaghi MA, Savoiardo M, Strada L: Unusual computerized tomography appearance of a carotid-cavernous fistula. Case report. J Neurosurg 58:435-437, 1983

46. Watanabe A, Ishii R, Suzuki Y, et al: The cerebral circulation in cases of carotid cavernous fistula. Findings of single photon emission computed tomography. Neuroradiology 32:108-113, 1990

47. Weber W, Henkes H, Berg-Dammer E, et al: Cure of a direct carotid cavernous fistula by endovascular stent deployment. Cerebrovasc Dis 12:272-275, 2001

48. Yamashita K, Taki W, Nishi S, et al: Transvenous embolization of dural caroticocavernous fistulae: technical considerations. Neuroradiology 35:475-479, 1993

Manuscript received July 2, 2003.

Accepted in final form September 8, 2003.

Address reprint requests to: Randall T. Higashida, M.D., University of California at San Francisco Medical Center, Room L352, 505 Parnassus Avenue, San Francisco, California 94143-0628. email: randall.higashida@radiology.ucsf.edu. 